\title{
Potential risk factors for diabetic neuropathy: a case control study Fargol Booya $^{\dagger 1}$, Fatemeh Bandarian ${ }^{\dagger 1}$, Bagher Larijani ${ }^{* 2}$, Mohammad Pajouhi ${ }^{\dagger 2}$, Mahdi Nooraei ${ }^{\dagger 3}$ and Jamshid Lotfi ${ }^{\dagger 4}$
}

\begin{abstract}
Address: ${ }^{1}$ Researcher, Endocrinology and Metabolism Research Center (EMRC), Tehran University of Medical Sciences, Tehran, Iran, ${ }^{2}$ Professor of Internal Medicine, Endocrinology, Endocrinology and Metabolism Research Center, Tehran University of Medical Sciences, Tehran, Iran, ${ }^{3}$ Epidemiologist, Endocrinology and Metabolism Research Center, Tehran University of Medical Sciences, Tehran, Iran and ${ }^{4}$ Neurologist, Department of Neurology, Shariati hospital, Tehran University of Medical Sciences, Tehran, Iran
\end{abstract}

Email: Fargol Booya - fargolbooya@yahoo.com; Fatemeh Bandarian - fbandarian@sina.tums.ac.ir; Bagher Larijani* - emrc@sina.tums.ac.ir; Mohammad Pajouhi - emrc@sina.tums.ac.ir; Mahdi Nooraei - emrc@sina.tums.ac.ir; Jamshid Lotfi - emrc@sina.tums.ac.ir

* Corresponding author †Equal contributors

Published: 10 December 2005

BMC Neurology 2005, 5:24 doi:10.1 186/147/-2377-5-24
Received: 02 July 2005

Accepted: 10 December 2005

This article is available from: http://www.biomedcentral.com/I47/-2377/5/24

(C) 2005 Booya et al; licensee BioMed Central Ltd.

This is an Open Access article distributed under the terms of the Creative Commons Attribution License (http://creativecommons.org/licenses/by/2.0), which permits unrestricted use, distribution, and reproduction in any medium, provided the original work is properly cited.

\begin{abstract}
Background: Diabetes mellitus type II afflicts at least 2 million people in Iran. Neuropathy is one of the most common complications of diabetes and lowers the patient's quality of life. Since neuropathy often leads to ulceration and amputation, we have tried to elucidate the factors that can affect its progression.

Methods: In this case-control study, I 10 diabetic patients were selected from the Shariati Hospital diabetes clinic. Michigan Neuropathic Diabetic Scoring (MNDS) was used to differentiate cases from controls. The diagnosis of neuropathy was confirmed by nerve conduction studies (nerve conduction velocity and electromyography). The multiple factors compared between the two groups included consumption of angiotensin converting enzyme inhibitors (ACEI), blood pressure, serum lipid level, sex, smoking, method of diabetes control and its quality.

Results: Statistically significant relationships were found between neuropathy and age, gender, quality of diabetes control and duration of disease ( $P$ values in the order: $0.04,0.04,<0.00 \mathrm{I}$ and 0.005). No correlation was found with any atherosclerosis risk factor (high BP, hyperlipidemia, cigarette smoking).

Conclusion: In this study, hyperglycemia was the only modifiable risk factor for diabetic neuropathy. Glycemic control reduces the incidence of neuropathy, slows its progression and improves the diabetic patient's quality of life. More attention must be paid to elderly male diabetic patients with poor diabetes control with regard to regular foot examinations and more practical education.
\end{abstract}

\section{Background}

Diabetes mellitus (DM) is one of the most widespread chronic diseases in the world. Nearly $7.5 \%$ of Iranian people are affected by DM type II [1]. DM has two types of complications: microvascular and macrovascular. One of the most frequently-occurring microvascular complications is diabetic neuropathy (DN), of which the most common type is distal symmetrical neuropathy or polyneuropathy. This results in significant disability and morbidity $[2,3]$. Complications of $\mathrm{DN}$ include severe 
Table I: Comparison of variables between patients with and without diabetes neuropathy

\begin{tabular}{llll}
\hline Variables & Patients with neuropathy & Patients without neuropathy & p-value \\
\hline Age (year) & $58.4 \pm 10.5$ & $55 \pm 10.7$ & 0.04 \\
Sex & $61.8 \% \mathrm{~F}, 38.2 \% \mathrm{M}$ & $81.8 \% \mathrm{~F}, 18.2 \% \mathrm{M}$ & 0.02 \\
FBS (mg/ml) & $143.6 \pm 60.2$ & $130.8 \pm 63.5$ & 0.13 \\
BS2hpp (mg/ml) & $252 \pm 82$ & $234 \pm 86$ & 0.09 \\
HbA $\mathbf{l c}(\%)$ & $8.2 \pm 2.5$ & $7.9 \pm 2.7$ & 0.42 \\
Total cholesterol (mg/d) & $214.9 \pm 26.4$ & $193.3 \pm 29.3$ & 0.001 \\
Duration of disease (year) & $14.2 \pm 7.4$ & $11.6 \pm 9.4$ & 0.03 \\
MNDs Score & $5.5 \pm 1.4$ & $1.1 \pm 5.9$ & 0.0001 \\
\hline
\end{tabular}

pain, loss of ambulation and increased risk of foot ulceration and amputation.

Incidences of polyneuropathy have been reported in 10$50 \%$ of patients with diabetes [3]. At the time of diagnosis, neuropathy is present in $10 \%$ of diabetic patients and overall in $50 \%$ of patients with a 25 -year history of the disease $[4,5]$. Life-time risk of foot amputation is $15 \%$ in patients with diabetic polyneuropathy [5]. Polyneuropathy is the first step in the generation of diabetic foot ulcer. It produces an anesthetic foot defective in proprioception and therefore exposed to inappropriate loading. Foot ulcers develop in risk areas that are exact pressure points [6].

Different hypotheses have been proposed to explain the various modes of progression of DN. It has been suggested that consumption of oral hypoglycemic agents such as glyburide [7] and angiotensin converting enzyme inhibitors (ACEI) inhibit the progression of neuropathy irrespective of blood glucose level [8-10]. Atherosclerosis risk factors are thought to promote DN [6]. The induction of mononeuropathy is closely associated with high blood pressure (BP), hyperlipidemia and cigarette smoking [6]. Since neuropathy can lead to ulceration and amputation, we have tried to assess the relationships between these risk factors and sensory/motor polyneuropathy. Early diagno- sis and treatment of DN is important for preventing secondary complications and improving quality of life.

\section{Methods}

One hundred and ten diabetic patients participated in this case-control study (55 patients in each group). Controls and cases were chosen from the Shariati Hospital diabetes outpatient clinic by simple randomized sampling. A control subject was a diabetic patient with no evidence of DN, and a case was a diabetic patient with neuropathy. The patients' ages ranged between 20 and 80 years. Exclusion criteria were creatinine $>2 \mathrm{mg} / \mathrm{dl}$, specific neurological disease (M.S, stroke, etc.), other causes of neuropathy ( $B_{12}$ deficiency, alcoholism, etc.), loss of dorsalis pedis pulses and less than 5 years duration of disease. Informed consent was completed by all participants before they were enrolled in the study. The study design was approved by the research ethics committee of the Endocrinology and Metabolism Research Center of Tehran University of Medical Sciences.

In order to differentiate between cases and controls, Michigan Neuropathic Diabetic Scoring (MNDS) was used [11]. This system gives a score in the range $0-8$, based on evaluation of 4 different factors in the each leg. These factors are: appearance of foot (dry skin, callus, deformities, fissure, and infection), presence of ulcer, Achilles tendon reflex and vibration perception in the great toe (measured

Table 2: Frequency of potential diabetic neuropathy risk factors in 110 diabetic patients

\begin{tabular}{|c|c|c|}
\hline Variables & & Prevalence (\%) \\
\hline Hypertension & & 41.8 \\
\hline ACEI usage & & 28.2 \\
\hline \multicolumn{3}{|l|}{$\mathrm{HbA}_{1 \mathrm{C}}$} \\
\hline & Poor control & 45.5 \\
\hline & Faire control & 18.2 \\
\hline & Good control & 36.3 \\
\hline \multicolumn{3}{|l|}{ Cigarette smoking } \\
\hline & None & 78.2 \\
\hline & More than 6 months of withdraw & 14.5 \\
\hline & less than 10 cigarette/day & 7.3 \\
\hline Hypercholesterolemia & & 42.7 \\
\hline
\end{tabular}




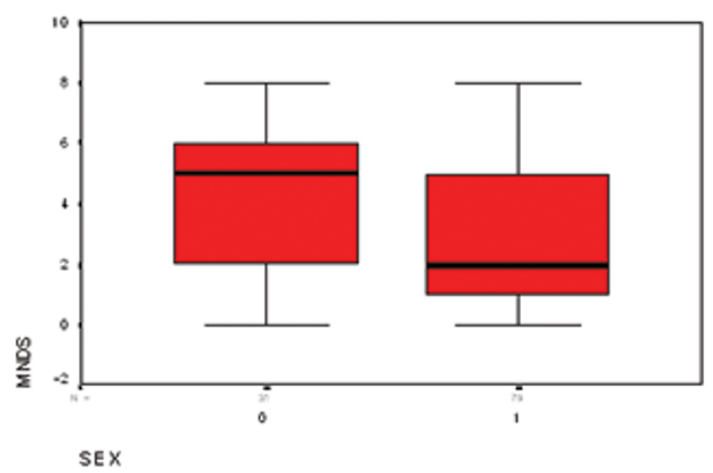

Figure I

Box plot demonstrating relationship between MNDS score and $\operatorname{sex}(0=$ male, $I=$ female $)$. The dark line in the plot is equivalent to mean MNDS score. Average score is higher in males.

with a $128 \mathrm{~Hz}$ tuning fork). Each component may be given a score of 0.5 or 1 on the basis of the relevant signs. This scoring system has sensitivity and specificity of nearly $95 \%$ [12]. A neuropathic foot usually scores 3 or higher, a normal foot 2.5 or lower. Cases with a diagnosis of neuropathy according to the Michigan scoring system were confirmed by nerve conduction studies (EMG-NCV). For this purpose, nerve conduction velocity, amplitude, duration and latency were assessed in 5 sensory/motor nerves (Median, Ulnar, Tibial, Proneal and Sural) on the nondominant side of the body. At least one abnormal test in more than one of these nerves was considered indicative of neuropathy [11].

Detailed information on each patient's age, sex, type and duration of diabetes mellitus, mode of treatment (insulin, oral hypoglycemic agents or both), degree of blood glucose control (bad, fair, good), presence of hypertension, hyperlipidemia (serum total cholesterol level), ACEI consumption and smoking was recorded and compared between cases and controls.

The quality of diabetes control was classified according to the average glycosylated hemoglobin $\left(\mathrm{HbA}_{1 \mathrm{C}}\right)$ over the previous year. Average $\mathrm{HbA}_{1 \mathrm{C}} \leq 7.5$ was considered good quality control; average $7.6<\mathrm{HbA}_{1 \mathrm{C}} \leq 9$ was considered fair control, and average $\mathrm{HbA}_{1 \mathrm{C}} \geq 9.1$ poor control. All necessary data were retrieved from the patient records in the diabetes outpatient clinic of Shariati Hospital. Patients with $\mathrm{BP} \geq 140 / 90$ were considered hypertensive. Patients with total cholesterol $\geq 250$ were considered hyperlipidemic. $\mathrm{HbA}_{1 \mathrm{C}}$ was measured by HPLC. The total cholesterol level was measured by calorimetry (Pars Azmoon
Table 3: The association of sex, duration of disease and quality of diabetes control with diabetic neuropathy (result of multivariate analysis, logistic regression)

\begin{tabular}{lccc}
\hline Variable & $\beta$ & P-value & Odds ratio \\
\hline $\begin{array}{l}\text { Sex } \\
\text { (male/female) }\end{array}$ & 1.56 & 0.04 & 2.9 \\
$\begin{array}{l}\text { Duration of disease } \\
\begin{array}{l}\text { Quality of diabetes control } \\
\text { (fair/bad) }\end{array}\end{array}$ & -2.1 & 0.005 & 1.1 \\
$\begin{array}{l}\text { Quality of diabetes control } \\
\text { (good/bad) }\end{array}$ & -1.2 & 0.04 & 0.001 \\
\begin{tabular}{l} 
Constant \\
\hline
\end{tabular} & -0.54 & 0.29 & 1.7 \\
\hline
\end{tabular}

kit), and fasting blood sugar (FBS) by the glucose oxidase method (Pars Azmoon kit).

SPSS 10 software was used for data entry and analysis. Since multiple factors were analyzed, multivariate analysis was used. Logistic regression was the appropriate mode for analyzing the multiple risk factors in cases and controls

\section{Results}

Of the 110 patients, $78 \%$ (79) were female and 22\% (31) were male. The mean age was $55.1 \pm 13.2$ (20-80 years). All but one of the patients had type II DM. Mean fasting blood glucose and average duration of disease in the study population were $140.5 \pm 8 \mathrm{mg} / \mathrm{dl}$ and $12.9 \pm 7$ years, respectively. Table 1 shows age, duration of disease, mean FBS, mean 2 hour post-parendial blood glucose (BS2hpp), $\mathrm{HbA}_{1 \mathrm{C}}$ and total cholesterol in cases and controls. Table 2 shows the frequency of potential risk factors for polyneuropathy in the study population. No significant relationships were found between distal symmetric sensory/motor polyneuropathy and cigarette smoking, ACEI consumption, BP or cholesterol level.

Multivariate analysis revealed statistically significant relationships between DN and age, gender, degree of diabetes control and duration of disease (P values: 0.04, 0.04, < 0.001 and 0.005 , respectively). Neuropathy was more frequent in men than women (odds ratio male/female 2.9, figure 1). The multivariate analysis results are shown in Table 3.

Poor diabetes control increases the likelihood of neuropathy 0.3 times (odds ratio good control/bad control 0.3 and fair/bad 0.2). Figure 2 shows the relationship between quality of diabetes control (good, fair and bad) and MNDS score. Each additional year of disease increases the likelihood of neuropathy 1.1-fold. 


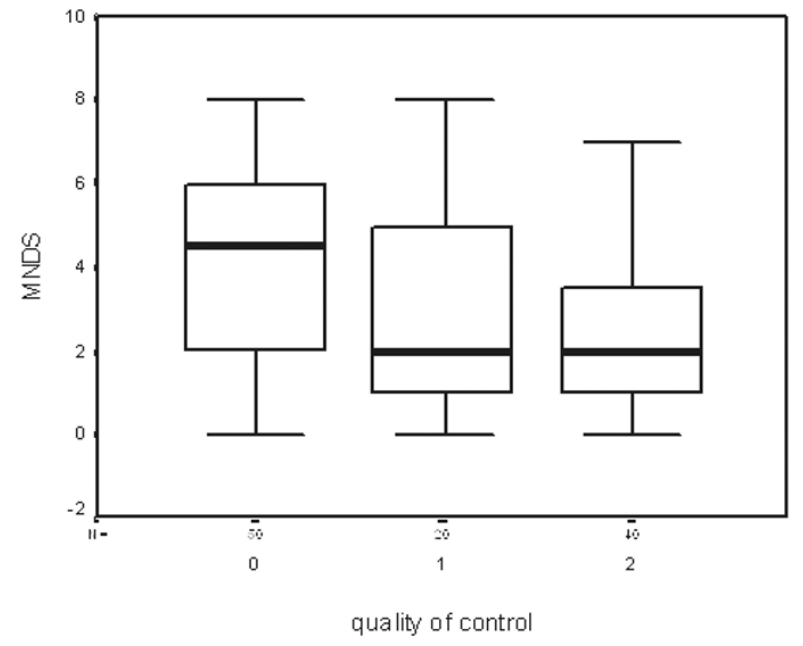

Figure 2

Box plot demonstrating relationship between MNDS score and quality of diabetes control $(0=$ poor, $I=$ fair, $2=$ good $)$. The dark line in the plot is equivalent to mean MNDS score. Average score is higher in poor control of diabetes.

\section{Discussion}

Diabetic polyneuropathy is a common complication of DM with high morbidity and impairment of quality of life. Tesfye et al. [13] studied 3,250 diabetic patients and reported an overall prevalence of peripheral neuropathy in $28 \%$ of them. The condition was significantly associated with age, duration of disease, height, diastolic blood pressure, smoking status, low HDL cholesterol level, high triglyceride level and $\mathrm{HbA}_{1 \mathrm{C}}$.

The Ashok study [14] showed significant relationships only with age and duration of disease. No other association was detected. Other studies have shown associations of neuropathy with age [14-19], duration of disease [14$20]$, metabolic control [15,18-21], height $[15,22,23]$, cigarette smoking $[15,19,24]$, retinopathy $[15,21]$ and reduced HDL level [15]. The results of the present study confirm previous reports regarding the association of neuropathy with male gender, age, glycemic control $\left(\mathrm{HbA}_{1 \mathrm{C}}\right)$ and duration of disease. Our data are also concordant with the DCCT (Diabetes Control and Complications Trial) [25] and UKPDS (United Kingdom Prospective Diabetes Study) results [26], which used EMG-NCV to identify neuropathic patients. Our finding that male gender is associated with neuropathy is consistent with the DCCT report [25]. Therefore, it can be concluded that MNDS criteria can be used with high confidence as an outpatient screening method. In our study, no statistically significant relationship was found between peripheral neuropathy and ACEI or consumption of oral hypoglycemic agents. Polyneuropathy was not significantly related to BP, smok- ing or hyperlipidemia. Most of our patients were nonsmokers, so it was impossible to examine the possible association between smoking and neuropathy critically.

Further studies using a randomized clinical trial are needed to evaluate the effects of ACEI and oral hypoglycemic agents on neuropathy.

\section{Conclusion}

Since hyperglycemia is a modifiable risk factor for diabetic neuropathy, intensive glycemic control is the most effective established therapy for reducing the incidence or slowing the progression of neuropathy and improving quality of life in diabetic patients. According to the results of the present study, better care should be given to elderly male diabetic patients with poor diabetic control in terms of regular foot examinations and more practical education.

\section{Competing interests}

The author(s) declare that they have no competing interests.

\section{Authors' contributions}

FB and FB: drafted the manuscript and coordinated the study

$\mathrm{BL}, \mathrm{MP}, \mathrm{JL}$ : conceived of the study and participated in the design of the study

$\mathrm{MN}$ : performed statistical analysis

All authors read and approved the final manuscript

\section{Acknowledgements}

The authors are grateful to the Endocrinology and Metabolism Research Center (EMRC) for financial support of the EMG-NCV procedure.

\section{References}

I. Larijani B, Zahedi F: Epidemiology of diabetes mellitus in Iran. Iranian Journal of Diabetes and Lipid Disorders 2002, I: I-8.

2. Braunwald E, Fauci AS, Kasper DL, editors: Harrison Principles of Internal Medicine I5th edition. New York, McGraw- Hill; 200I.

3. Dyck PJ, Thomas PK: Diabetic Neuropathy 2nd edition. Philadelphia, WB. Saunders; 1999.

4. Dyck PJ, Kratz KM, Karnes JL, Litchy WJ, Klein R, Pach JM, Wilson DM, O'Brien PC, Melton LJ 3rd, Service FJ: The prevalence by staged severity of various types of diabetic neuropathy, retinopathy, and nephropathy in a population-based cohort: the Rochester Diabetic Neuropathy Study. Neurology 1993, 43:817-824.

5. Feldman EL, Russell JW, Sullivan KA, Golovoy D: New insights into the pathogenesis of diabetic neuropathy. Curr Opin Neurol 1999, 12:553-563.

6. Kahn RC, Weir CG, ed: Diabetes Mellitus I3th edition. Pennsylvania, Lea \& Febiger inc; 1994.

7. Quasthoff S: The role of axonal ion conductances in diabetic neuropathy: a review. Muscle Nerve 1998, 21:1246-1255.

8. Martinez-Blasco A, Bosch-Morell F, Trenor C, Romero F): Experimental diabetic neuropathy: role of oxidative stress and mechanisms involved. Biofactors 1998, 8:4I-43. 
9. Qiang X, Satoh J, Sagara M, Fukuzawa M, Masuda T, Miyaguchi S, Takahashi K, Toyota T: Gliclazide inhibits diabetic neuropathy irrespective of blood glucose levels in treptozotocin-induced diabetic rats. Metabolism 1998, 47:977-98I.

10. Cameron NE, Cotter MA, Horrobin DH, Tritschler HJ: Effects of alpha-lipoic acid on neurovascular function in diabetic rats: interaction with essential fatty acids. Diabetologia 1998, 41:390-399.

II. Feldman EL, Stevens MJ, Thomas PK, Brown MB, Canal N, Greene DA: A practical two-step quantitative clinical and electrophysiological assessment for the diagnosis and staging of diabetic neuropathy. Diabetes Care 1994, 17:| 28I-1289.

12. Lunetta M, Le Moli R, Grasso G, Sangiorgio L: A simplified diagnostic test for ambulatory screening of peripheral diabetic neuropathy. Diabetes Res Clin Pract 1998, 39:165-172.

13. Tesfaye S, Stevens LK, Stephenson JM, Fuller JH, Plater M, lonescuTirgoviste C, Nuber A, Pozza G, Ward JD: Prevalence of diabetic peripheral neuropathy and its relation to glycemic control and potential risk factors. The Euro Diab IDDM complications study. Diabetologia 1996, 39: I377-1384.

14. Ashok S, Ramu M, Deepa R, Mohan V: Prevalence of neuropathy in type 2 diabetic patients attending a diabetes centre in South India. J Assoc Physicians India 2002, 50:546-550.

15. Maser RE, Steenkiste AR, Dorman JS, Nielsen VK, Bass EB, Manjoo Q, Drash AL, Becker DJ, Kuller LH, Greene DA, et al.: Epidemiological correlates of diabetic neuropathy. Report from Pittsburgh Epidemiology of Diabetes Complications Study. Diabetes 1989, 38: $|456-| 46 \mid$.

16. Boulton AJM, Knight G, Drury J, Ward JD: The prevalence of symptomatic diabetic neuropathy in an insulin- treated population. Diabetes Care 1985, 8: I25-128.

17. Knuiman MW, Welborn TA, McCann VJ, Stanton KG, Constable IJ: Prevalence of diabetic complications in relation to risk factors. Diabetes 1986, 35: /332-1339.

18. Franklin GM, Kahn LB, Baxter J, Marshall JA, Hamman RF: Sensory neuropathy in non-insulin-dependent diabetes mellitus. The San Luis Valley Diabetes Study. Am J Epidemiol 1990, 1 3 1:633-643.

19. Barbosa AP, Medina JL, Ramos EP, Barros HP: Prevalence and risk factors of clinical diabetic polyneuropathy in a Portuguese primary health care population. Diabetes Metab 200I, 27:496-502.

20. Manuel Malacara J, Eugenia Davalos L, Cervantes F, Castillo J, Velasco E: Risk factors of the complications of diabetes mellitus. Rev Invest Clin 1991, 43:3-9.

21. Pirart J: Diabetes mellitus and its degenerative complications: a prospective study of 4400 patients observed between 1947 and 1973. Diabetes Care 1978, I:168-|88. 252-263

22. Hyllienmark L, Brismar T, Ludvigsson : Subclinical nerve dysfunction in children and adolescents with IDDM. Diabetologia 1995 38:685-692.

23. Sosenko JM, Gadia MT, Fournier AM, O'Connell MT, Aguiar MC, Skyler JS: Body stature as a risk factor for diabetic sensory neuropathy. Am J Med 1986, 80:103I-1034.

24. Eliasson B: Cigarette smoking and diabetes. Prog Cardiovasc Dis 2003, 45:405-413.

25. The DCCT Research Group: Factors in the development of diabetic neuropathy in feasibility phase of Diabetes Control and Complications Trial (DCCT). Diabetes 1988, 37:476-48।

26. Nasr CE, Hoogwerf BJ, Faiman C, Reddy SS: United Kingdom Prospective Diabetes Study (UKPDS). Effects of glucose and blood pressure control on complications of type 2 diabetes mellitus. Cleve Clin J Med 1999, 66:247-253.

\section{Pre-publication history}

The pre-publication history for this paper can be accessed here:

http://www.biomedcentral.com/1471-2377/5/24/prepub

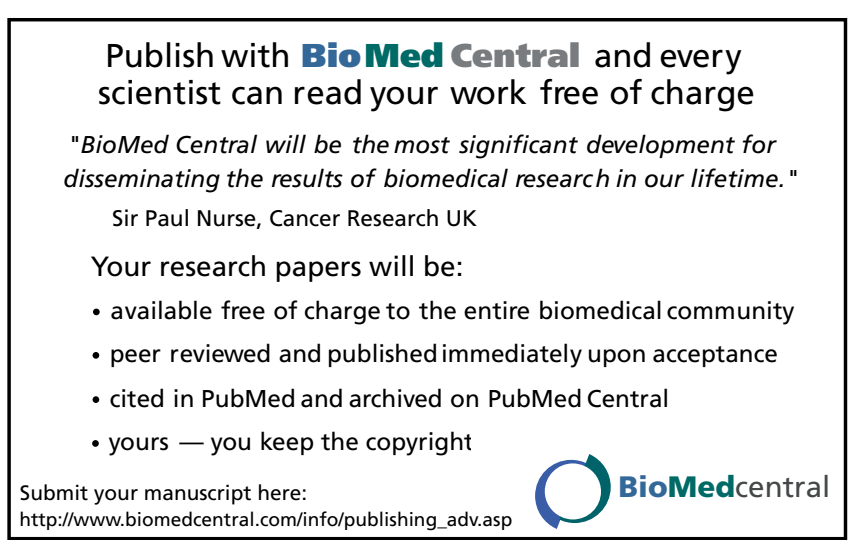

